\title{
LA OFERTA TURÍSTICA COMPLEMENTARIA EN LOS DESTINOS TURÍSTICOS ALICANTINOS: IMPLICACIONES TERRITORIALES Y OPCIONES DE DIVERSIFICACIÓN
}

\author{
Carlos Javier Baños Castiñeira
}

\section{RESUMEN}

El grado de madurez alcanzado por los destinos turísticos clásicos adscritos al modelo de sol y playa masivo, aconseja el desarrollo de medidas de política turística que permitan la redefinición de los productos turísticos litorales. En este sentido, se plantea el aspecto de la introducción de elementos de la denominada oferta turística complementaria como un argumento adecuado en pro de la diversificación de los mismos. Asimismo, la importancia otorgada por la demanda turística a nuevas fórmulas de ocio, señala al turismo como una actividad susceptible de incorporar políticas territoriales orientadas al reequilibrio socioeconómico de espacios regionales, en una dialéctica litoral-interior basada en la complementariedad de las ofertas turísticas desarrolladas a partir de las potencialidades endógenas locales.

Palabras clave: oferta turística complementaria, agotamiento de destinos turísticos, complementariedad de ofertas.

\section{RÉSUMÉ}

L'apuisement des destins touristiques balneaires conseille le développement des mesures orientées vers la redéfinition des produits touristiques balneaires. Doncs, on expose l'insertion des offres touristiques complementaires comme une voie adéquate pour leur diversification. Pareillement, l'importance des nouveaux experiences de loisir remarquent le tourisme comme une activité susceptible de rattacher des politiques territoriales orientées vers le reéquilibre sociaux et économique des espaces regionaux, dans une dialectique littoral-interieur basée à la function complementaire des offres touristiques developpées a partir des potentialités locales.

Mots clefs: offre touristique complementaire, apuisement des destins touristiques, complementarieté des offres. 


\section{Rasgos básicos de la oferta turística de la provincia de Alicante}

La evolución de la actividad turística en los espacios litorales survalencianos ha tenido como principal elemento definidor al alojamiento de carácter extrahotelero. En efecto, en el modelo turístico desarrollado en la franja costera alicantina ha primado la creación de plazas de alojamiento como la esencial actividad económica asociada al turismo. De esta manera, los esfuerzos empresariales dirigidos a la producción de espacio turístico se han limitado al desarrollo de operaciones inmobiliarias, construcción y venta de vivienda, sin más contenido turístico que la proximidad al recurso. Por otra parte, estas operaciones de marcado carácter inmobiliario, en la mayoría de las ocasiones alentadas por las administraciones locales que han visto en ellas una fórmula idónea para engrosar las arcas municipales de forma rápida, han conformado un tipo de oferta de alojamiento de carácter no comercial $^{1}$, situada al margen de cualquier control y seguimiento por parte de la administración (MAPA 1).

En el Cuadro 1 se señala, de manera únicamente cuantitativa, el volumen de la oferta de alojamiento de la provincia de Alicante y se constata, de forma rotunda, el peso que posee la oferta de alojamiento anteriormente denominada alegal o extralegal y a la que actualmente hay que referirse como ilegal. Ese desequilibrio se ve, si cabe, agravado al incorporar el dato de que el sesenta y cinco por ciento de las plazas de alojamiento hotelero pertenecen a la ociurbe de Benidorm.

Cuadro 1

OFERTA DE ALOJAMIENTO EN LA PROVINCIA DE ALICANTE (N DE PLAZAS). Diciembre, 1996

\begin{tabular}{|c|c|c|c|c|c|}
\hline & \multicolumn{2}{|c|}{ Legal } & \multicolumn{2}{|c|}{ Ilegal } & \\
\hline & Total & $\%$ & Total & $\%$ & \\
\hline HOTELES & 48.512 & 5,45 & & & \\
\hline HOSTALES & 2.281 & 0,25 & & & \\
\hline CAMPINGS & 24.321 & $2 ’ 73$ & & & \\
\hline APARTAMENTOS & 63.870 & $7 ' 17$ & 751.146 & $84^{\prime} 4$ & \\
\hline TOTAL & 138.984 & $15^{\prime} 6$ & 751.146 & $84^{\prime} 4$ & 890.130 \\
\hline
\end{tabular}

FuENTE: Elaboración propia. Agència Valenciana del Turisme. Fundación Cavanilles de Altos Estudios Turísticos.

El resultado final de esta dinámica inmobiliario-turística ha sido la compactación urbanística del litoral alicantino, en lo que se ha denominado «dorsal urbano-turística del litoral» que ha tenido efectos polarizadores acumulativos en lo que se refiere a la inserción de infraestructuras, desarrollo de dinámicas económicas, concentración de impactos ambientales en la franja litoral, lo cual ha supuesto el agravamiento de las distancias que separan, territorial y socioeconómicamente, el interior provincial de los espacios litorales

1 Diferentes autores (IRIBAS, 1995; VERA Y OTROS, 1995) han señalado la existencia de una oferta de alojamiento casi exclusivamente de carácter extralegal como una de las causas principales no sólo de la baja calidad de los productos turísticos alicantinos sino también de la atonía en la generación de dinámicas económicas turísticas, al margen de las meramente relacionadas con la construcción y venta de viviendas. 

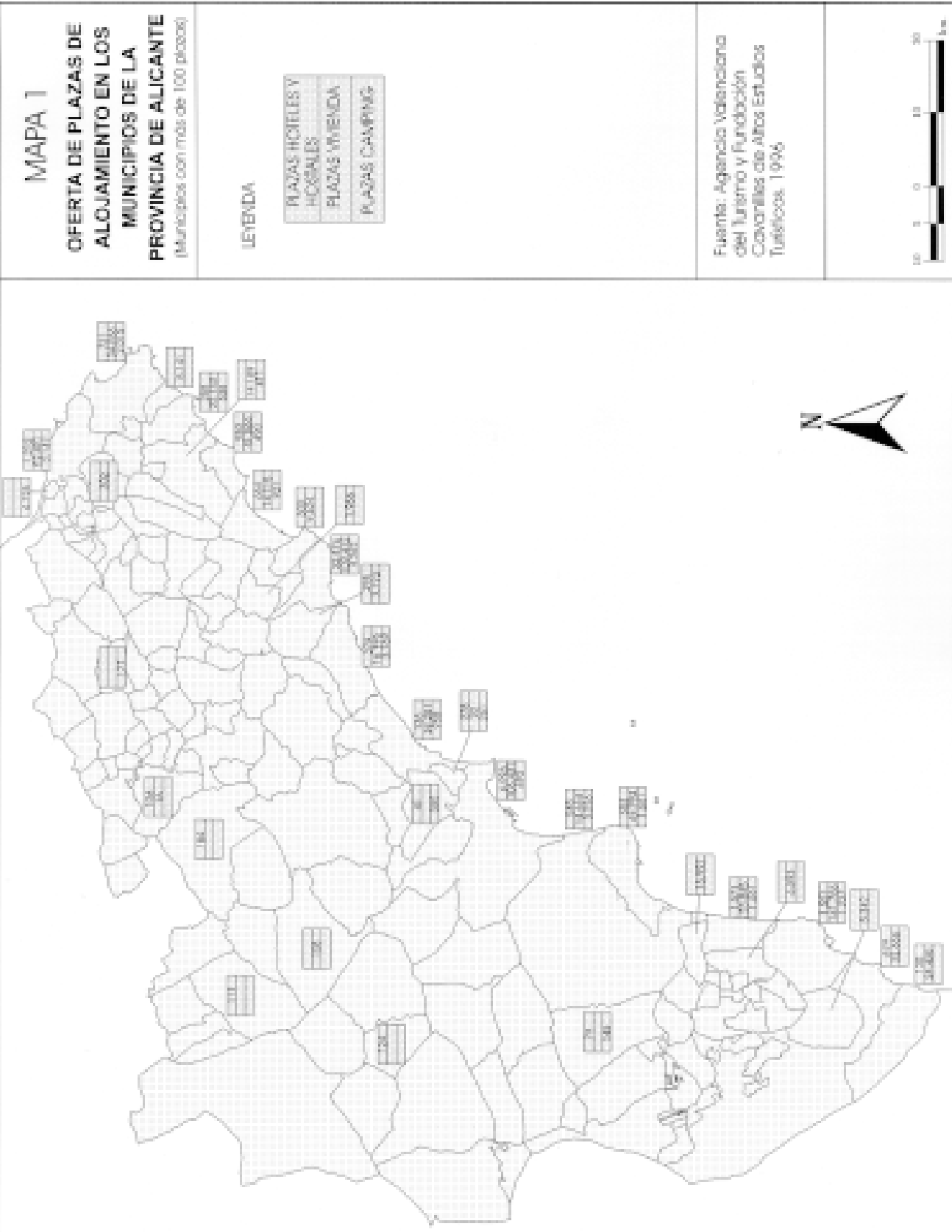
(VERA; CRUZ; BAÑOS: 1995), y ha provocado un importante decrecimiento en los activos poblacionales de estas áreas interiores (MAPA 2).

El modelo de desarrollo turístico descrito en los párrafos anteriores tiene, en la actualidad, como principales características su carácter masivo, escasa especialización de los productos y orientación a segmentos de demanda de clase social media-baja. Lógicamente, la implantación y desarrollo de este modelo turístico tuvo su razón de ser en la existencia de mercados que justificaban, con sus demandas de poca o ninguna complejidad, la creación de estas ofertas.

Sin embargo, las mejoras socioeconómicas operadas sobre los tradicionales mercados exteriores de los productos turísticos englobados entre los modelos turísticos de «sol y playa masivo» - fundamentalmente clases medias europeas - han supuesto la introducción de importantes cambios en el «comportamiento turístico» de los mismos, en lo que Torres Bernier ha definido como «megatendencias culturales» ${ }^{2}$. En definitiva, ello ha supuesto el incremento y la mayor complejidad de las exigencias del turista, al que no se satisface ya con el acceso al mero disfrute del recurso ecológico.

Así pues, el clásico modelo de turismo masivo de sol y playa, instalado en la mayor parte del litoral Mediterráneo español, de filiación inmobiliaria, presenta en la actualidad ofertas excesivamente generalistas, sometidas a fluctuaciones de carácter coyuntural y relegadas al papel de satisfacer a las demandas menos exigentes y dinamizadoras de los espacios turísticos, fenómeno en progresión y que Donaire ha descrito para la Costa Brava respecto a los mercados del Este europeo.

Sin embargo, desde diferentes ámbitos científicos y técnicos se han propuesto estrategias orientadas a la dinamización de estos espacios. En este sentido, resulta difícil discutir que la vía de la cualificación de las ofertas turísticas se presenta como las más adecuadas, y aún menos discutible es la necesidad de diseñar políticas de reestructuración de una actividad que representa prácticamente el $9 \%$ del P.I.B. de la Comunidad Valenciana, sin incluir los efectos multiplicadores, o más del $11 \%$ del empleo.

Como vías adecuadas que permitan el desarrollo de una estrategia global de cualificación de los destinos turísticos se han señalado como preferentes las de la diversificación y diferenciación de los productos existentes. El desarrollo de estas acciones encaminadas a la revitalización de la actividad turística contempla, por lo general, dos tipos de actuaciones potenciación y desarrollo de nuevos productos, donde, por ejemplo, se insertan fórmulas turísticas relacionadas con el turismo rural, o acciones de reacondicionamiento de espacios turísticos consolidados, destinos litorales maduros, ante las que se inscriben intervenciones de dotación de equipamientos y servicios, recomposición de bordes marítimos, la apertura al mar de las poblaciones, técnicas de esponjamiento, recuperación de áreas portuarias degradadas ${ }^{3}$. Entre este tipo de actuaciones se incluyen aquellas orientadas a la creación de nuevos elementos de oferta, la denominada habitualmente oferta turística complementaria.

2 Señala Torres Bernier como «megatendencias culturales» más destacables: 1) la mayor exigencia de los turistas en todos los aspectos (acceso a información veraz y de calidad, calidad de los productos turísticos, calidad del entorno), 2) personalización de los viajes, 3) diversificación motivacional, 4) posicionamiento activo del turista y 5) sensibilización hacia los aspectos medioambientales.

3 En este sentido, resulta paradigmática la operación desarrollada en el frente litoral de la ciudad de Barcelona, fundamentalmente en el sector del Port Vell, aprovechando la coyuntura favorable propiciada por los Juegos Olímpicos de 1992. 


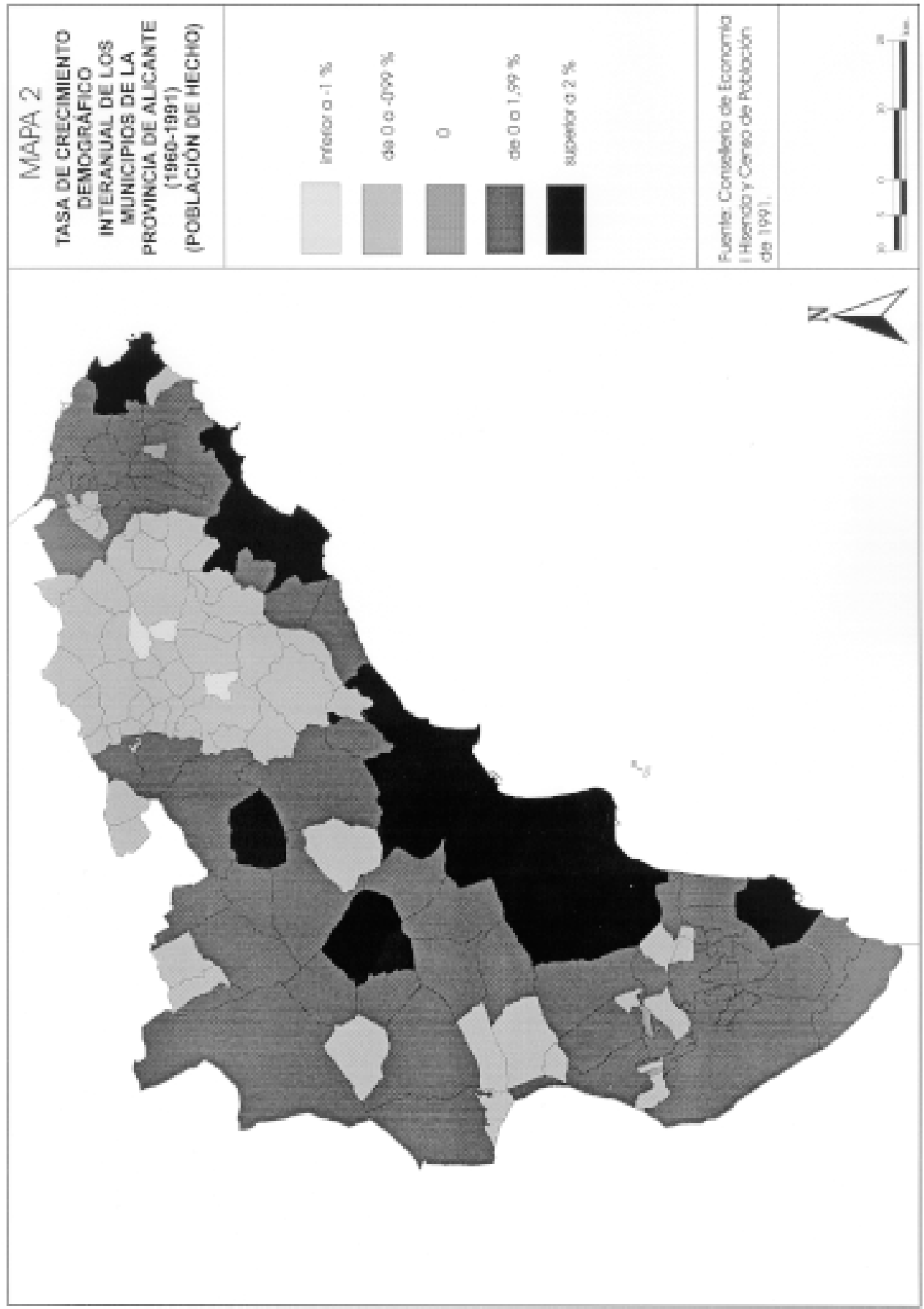




\section{La oferta turística complementaria en los modelos turísticos masivos de sol y playa}

Desde finales de la década de los años ochenta, coincidiendo con la mal denominada «crisis del turismo», investigadores del turismo de distintas disciplinas y técnicos asumen la importancia que para la reestructuración de destinos turísticos en fase de madurez posee la oferta turística complementaria. De esta manera, documentos de la importancia de CALVIÀ A BON PORT, Avance del Plan General de Ordenación del Municipio de Calvià ${ }^{4}$ o el Plan DIA Desarrollo Integral del Turismo Andaluz, introducen este tipo de ofertas como elementos objeto de ordenación.

Precisamente, en el segundo de estos trabajos, el Plan DIA, se remarca esa importancia de la oferta turística complementaria, al señalar que «La diversificación del producto turístico tiene su base en la oferta "complementaria», siendo ésta precisamente una de las causas principales de la «crisis» existente en el sector por su debilidad o desfase, pero también puede constituirse en la salida de la misma al provocar nuevos productos turísticos».

La consideración de las ofertas turísticas complementarias como elementos de importancia dentro de los productos turísticos es, pues, muy reciente. Durante la presente década es cuando esa idea empieza a cobrar visos de realidad al asumirla para sí, de manera paulatina, los agentes turísticos públicos y privados.

En la provincia de Alicante, el de las nuevas ofertas de ocio es un tema de gran actualidad, provocada fundamentalmente por la futura instalación de un gran parque de ocio en las proximidades de Benidorm. Sin embargo, la presencia de ofertas complementarias en el litoral alicantino, o al menos de piezas que habitualmente se han considerado como tales, se remonta incluso hasta treinta años atrás.

\subsection{La oferta complementaria en el modelo turístico de sol y playa masivo: el caso de Alicante}

No cabe duda que en el proceso de implantación de elementos de oferta turística complementaria se han seguido las lógicas marcadas por el desarrollo del modelo de sol y de playa masivo, es decir, el crecimiento ha venido dirigido por los impulsos de la demanda y se ha guiado únicamente por criterios señalados por la misma, por sus gustos y tendencias, sin que se valoraran potencialidades, recursos presentes o criterios de sostenibilidad futura de la actividad.

Desde los inicios de la actividad turística en el litoral alicantino hasta final de la década de los años ochenta, momento en que se produce la mencionada crisis por agotamiento de destinos/productos turísticos de filiación inmobiliaria, se distinguen dos fases respecto a la importancia otorgada por los agentes turísticos, ya sean públicos o privados, a los elementos que constituyen la oferta complementaria del turismo de sol y playa, las fórmulas de inserción de dichos elementos, así como de las características de los mismos.

\section{Del inicio del turismo hasta mediados los años setenta: sol, arena y mar}

Durante este periodo, las exigencias de la demanda estaban cubiertas mediante el alojamiento, la alimentación y, todo lo más, con la existencia de diferentes establecimientos de ocio nocturno (bares, discotecas, cafeterías, tablaos flamencos). Las magníficas propiedades físico-ecológicas del litoral alicantino bastaban para satisfacer los requeri-

4 En este trabajo de ordenación, se realiza una interesante propuesta de como, a diferentes escalas, la oferta complementaria puede servir para cualificar tanto el producto como el espacio turístico. 
mientos de los primeros turistas. Valores que actualmente se consideran de gran interés y que ofrecen grandes oportunidades de cara a la diversificación de los productos turísticos como son la naturaleza o la salud, eran entonces totalmente ignorados.

Así pues, la demanda de los productos turísticos del Mediterráneo español no enfatizaba la necesidad de disfrutar de elementos que permitiesen emplear el tiempo libre de una forma más o menos activa. Desde el lado de la oferta la consecuencia lógica será una clara atonía y escasa diversificación.

Por otro lado, durante el periodo objeto de análisis, el centro de la atención de los estudios de oferta turística fue el alojamiento, y más concretamente, el alojamiento hotelero. Los exámenes que sobrepasaran el límite del análisis estadístico de las plazas de alojamiento llegaban, a lo sumo, a referirse a las agencias de viajes. Así, Joan Cals, en una de las primeras obras que en España abordaron el estudio del turismo desde una perspectiva científica, Turismo y política turística en España: una aproximación, se refiere en el capítulo cuarto, dedicado exclusivamente a la oferta turística española, a dos grandes elementos de oferta: en primer lugar la oferta hotelera y, en segundo lugar, las agencias de viajes. Finalmente, un tercer subgrupo, denominado Otras empresas del sector, incluye acampamentos (sic) y apartamentos.

Desde mediados de los años setenta a la «crisis» de finales de los años ochenta: la oferta complementaria como reclamo inmobiliario

El segundo periodo identificado vendría definido por la inserción de importantes piezas de oferta, fundamentalmente puertos deportivos y campos de golf (MAPA 3) que, lejos de generar dinámicas propias que desencadenaran procesos de cualificación y diversificación del modelo turístico instalado, sirvieron únicamente como excusa para continuar con la simple venta del territorio en forma de inmueble.

\section{- Los puertos deportivos}

En efecto, desde principios de la década de los años setenta proliferan en el litoral mediterráneo español, y más concretamente en la costa de la provincia de Alicante, así como en el sector atlántico andaluz, instalaciones náutico-deportivas que, con la excusa de favorecer el desarrollo de un supuesto turismo de calidad, supuso la concentración de graves impactos ecológicos que se producen en áreas de gran delicadeza ambiental, no sólo por el hecho de la instalación portuaria en sí misma, ya de extrema gravedad en muchos casos, sino también por el paralelo desarrollo inmobiliario que estas actuaciones llevan parejas. Además, el deseado turismo de calidad que debía desarrollarse a partir de estas instalaciones no parece haber prosperado, al menos de forma significativa.

El ritmo de implantación de estas instalaciones a lo largo del litoral español fue vertiginoso, y es la ribera del mar Mediterráneo la que conoce un mayor desarrollo de estas infraestructuras náutico-deportivas. Desde la administración central se fomentó la creación de puertos deportivos ${ }^{5}$, con el fin de atraer a ese supuesto turismo de calidad, a través de la concesión de subvenciones a fondo perdido (hasta el $20 \%$ del presupuesto, en algunas ocasiones), adjudicación de créditos blandos y de la cesión a la propiedad privada de los terrenos ganados al mar con motivo de la construcción de los puertos deportivos (TORRES ALFOSEA, 1997).

5 Mediante Ley 55/1969, de 26 de abril, sobre Puertos Deportivos (en B.O.E. de 28 de abril). 


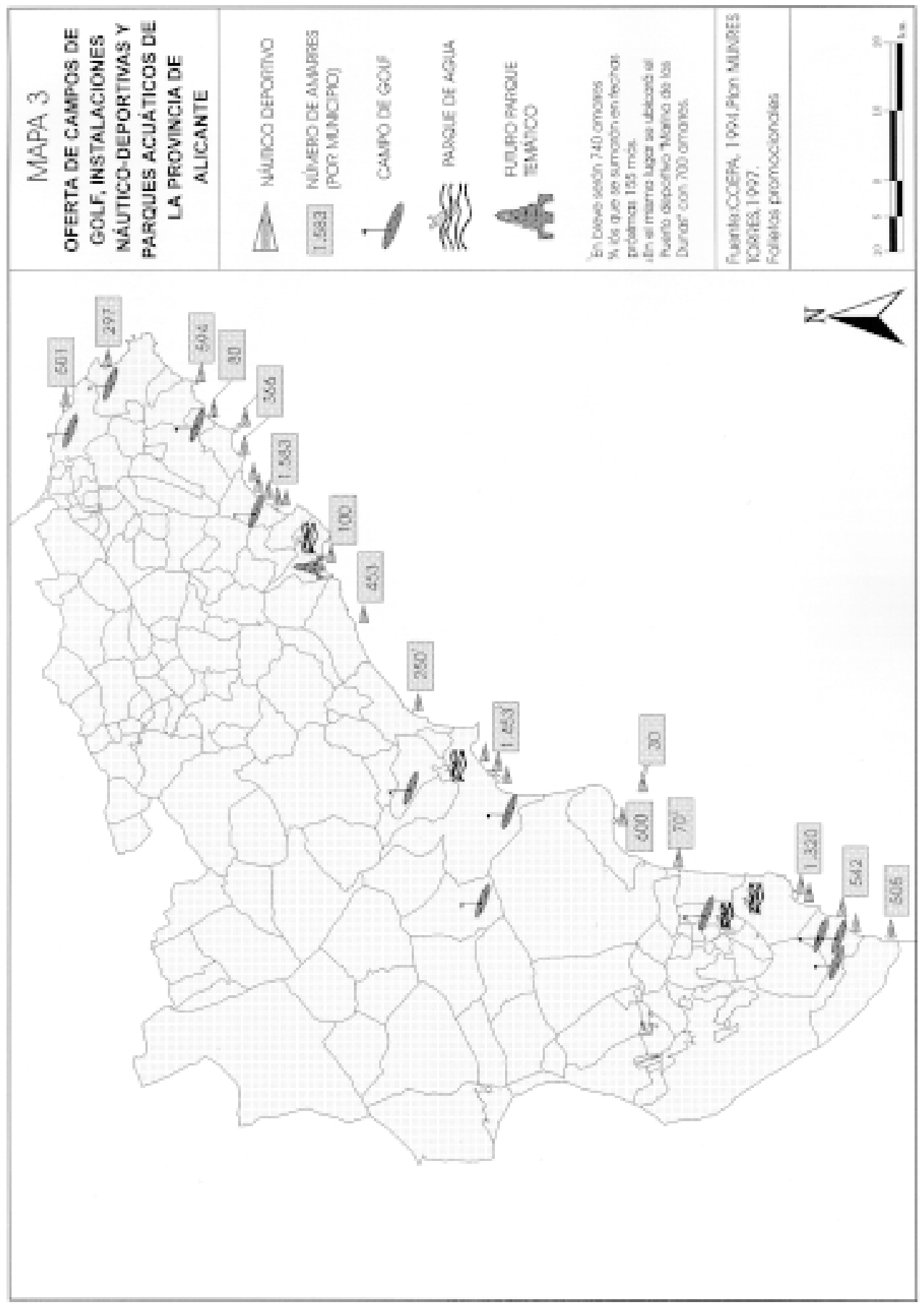


En la provincia de Alicante existen veinticinco instalaciones náutico deportivas de distinta envergadura y de gran diversidad en los servicios ofertados.

INSTALACIONES NÁUTICO DEPORTIVAS EN LA PROVINCIA DE ALICANTE

\begin{tabular}{|l|c|c|c|}
\hline Puerto & Municipio & $\begin{array}{c}\text { Total } \\
\text { amarres }\end{array}$ & $\begin{array}{c}\text { Amarres de } \\
\text { uso público }\end{array}$ \\
\hline C.N. DENIA & & 501 & 210 \\
C.N. JÁVEA & Denia & 297 & 100 \\
C.N. MORAIRA & Jávea & 152 \\
C.N. LES BASSETES & Teulada & 594 & 12 \\
C.N. PUERTO BLANCO & Benissa & 80 & 15 \\
C.N. CALPE & Calpe & 90 & 150 \\
C.N. ALTEA & Calpe & 276 & 168 \\
P. D. LUIS CAMPOMANES & Altea & 336 & 110 \\
LA GALERA & Altea & 552 & 15 \\
PORTET DE L'OLLÀ & Altea & 116 & \\
C.N. MASCARAT & Altea & 29 & \\
C.N. BENIDORM & Altea & 550 & \\
C.N VILLAJOYOSA & Benidorm & 100 & \\
C.N. EL CAMPELLO & Villajoyosa & 453 & \\
C.N. COSTA BLANCA & Campello & $250^{*}$ & \\
R.C.N. DE REGATAS & Alicante & 263 & 230 \\
MARINA DEPORTIVA DE ALICANTE & Alicante & $380^{* *}$ & \\
PUERTO DE TABARCA & Alicante & $810^{* *}$ & \\
C.N. DE SANTA POLA & Alicante & 30 & \\
PUERTO DE GUARDAMAR & Santa Pola & 600 & 300 \\
R.C.N. DE TORREVIEJA & Tuardamar del Segura & 70 & \\
P.D. MARINA INTERNACIONAL DE TORREVIEJA & Torrevieja & 460 & \\
C.N. DEHESA DE CAMPOAMOR & Torrevieja & 860 & \\
C.N. CABO ROIG & Orihuela & 328 & \\
C.N. TORRE DE LA HORADADA & Orihuela & 214 & 54 \\
\hline
\end{tabular}

P.D.: Puerto Deportivo. C.N.: Club Náutico R.C.N.: Real Club Náutico.

FuENTE: COEPA, 1994; TORRES, 1997; Folleto promocional NÁUTICA. Diputación de Alicante; Manual profesional del turismo de la Costa Blanca, 1997; folletos promocionales.

* En remodelación, verá ampliada su capacidad hasta 740 amarres. Las obras estuvieron paralizadas debido a problemas entre el Club Náutico y la Unión Temporal de Empresas que recibió la adjudicación de las mismas.

** En breve finalizará el traslado del Real Club de Regatas al varadero del puerto, con lo que pasará a albergar 400 puntos de amarre, al tiempo que Marina Deportiva de Alicante sumará tres nuevos pantalanes que le supondrán incrementar el número de amarres hasta alcanzar la cifra de 945 (TORRES ALFOSEA, 1997).

6 Se trata de una serie de amarres instalados en el tramo final de la desembocadura del río Segura. Aproximadamente en el mismo lugar (margen derecha de la desembocadura) está prevista la construcción, ya se han realizado las primeras obras de acondicionamiento del terreno, del puerto deportivo «Marina de las Dunas». Este puerto albergará 700 puntos de amarre y ocupará una superficie de $126.000 \mathrm{~m}^{2}$. 
Así pues, se constata la existencia de una oferta de puntos de amarre de considerable magnitud, casi nueve mil sólo en la provincia de Alicante. Si comparamos ese volumen de oferta con la existente en otros espacios que han conocido mayor éxito en el desarrollo del producto turístico náutico-deportivo, como por ejemplo la Comunidad Autónoma Andaluza, y más concretamente la provincia de Málaga, el sector de la Costa del Sol, podemos observar que toda la costa andaluza posee sólo tres mil puntos de amarre más que la provincia de Alicante, mientras que el litoral de la denominada Costa del Sol (provincia de Málaga) apenas posee la mitad de amarres que ésta.

Resulta cuando menos desproporcionado que instalaciones que podrían configurarse como elementos de marcado carácter estratégico, de cara a la recualificación y reactivación de modelos turísticos en fase de madurez, y que suponen importantes impactos para medio físico ecológico que los acoge, se desarrollen de manera desorganizada, sin que se entre a considerar aspectos que sobrepasen el beneficio empresarial generado por la actividad inmobiliaria, originada al socaire del incremento del precio del suelo producido por la ubicación de la instalación náutico-deportiva, ya que, como señala Torres, «uno de los efectos territoriales de la presencia de instalaciones del Club Náutico es que tienden a revalorizar las propiedades y negocios de las áreas colindantes, a través de los precios del suelo, aunque si no se derivan procesos especulativos, no cabe entenderlo como un efecto negativo, sino como simple fruto de la diferenciación espacial urbana».

El problema ha sido que, en muchas ocasiones, el puerto deportivo no ha constituido más que la excusa para, mediante el aprovechamiento del incremento del valor de los precios del suelo, reactivar el negocio inmobiliario. Sirvan dos ejemplos como muestra:

- en la Marina Internacional de Torrevieja, a los usuarios del puerto deportivo se les facilitan ventajosas condiciones para adquirir un apartamento o un bungalow en las proximidades de La Marina (TORRES ALFOSEA, 1997),

- en el caso del Puerto Deportivo Luis Campomanes (Altea), lo que en principio era una actuación de calidad, desde el punto de vista de la oferta turística, se está convirtiendo, con el paso del tiempo, en una urbanización más, que comienza a padecer problemas derivados de la densificación y dónde la calidad constructiva de las viviendas, la calidad ambiental y el nivel de servicios decrece rápidamente.

De esta manera, se producen hechos tan paradójicos como que en la provincia de Alicante quince de los veinte municipios litorales posean alguno de estos equipamientos náuticos? ${ }^{7}$ A pesar de ello, desde los gobiernos locales y el autonómico (caso de el puerto deportivo de Campello que cuenta para su reforma con financiación de la Generalitat Valenciana, o en el caso del propio puerto deportivo de Guardamar del Segura) se continúa fomentando la implantación de puertos deportivos, que promuevan un supuesto incremento en la calidad del destino/municipio turístico. Buen ejemplo de ello son los setecientos amarres que se están creando en la desembocadura del río Segura, en el municipio de Guardamar del Segura, curiosamente uno de los municipios que la demanda considera como de peor calidad turística en la Comunidad Valenciana ${ }^{8}$.

7 Los municipios que carecen de instalaciones náutico-deportivas en sus tramos litorales son: Els Poblets, Poble Nou de Benitaxell, Alfaz del Pi, Finestrat y Elche.

8 Encuestas a la demanda efectuadas en la realización de estudios como el Plan MUNRES (Programa de Revitalización de Municipios con Turismo Residencial) en 1994, o Las Bases para la Redacción del Plan Director de los Espacios Turísticos de la Comunidad Valenciana en 1995, señalan la baja consideración que los turistas tienen de este municipio. 
Los datos reflejados en párrafos anteriores hacen pensar que es éste un mercado/ producto (el turismo náutico-deportivo) de gran éxito en las costas alicantinas. Sin embargo, salvo contadas actuaciones, el turismo náutico no es un producto que en sí mismo haya conocido un importante desarrollo en la Costa Blanca. Por ejemplo, en el caso del último equipamiento de este tipo construido, Marina Deportiva de Alicante, el ritmo de venta de amarres no parece alcanzar el nivel previsto en un principio por la empresa titular.

Todo ello ha venido a negar las optimistas (y en algunos casos disparatadas) expectativas que apenas hace una década se tenían respecto a este segmento de mercado/producto. Estudios realizados desde la Secretaría General de Turismo hasta el año $1987^{9}$, valoraban para el sector de costa comprendido entre el Cabo de Palos y el cabo de San Antonio, es decir, prácticamente el espacio constituido por la Costa Blanca salvo el área de el Mar Menor, un déficit de puntos de amarre de 8.355 , en un momento en que ya existía una capacidad de acogida de 6.535 amarres instalados en puertos deportivos o zonas deportivas de puertos del Estado. Se consideraba que tanto la zona norte, limitada por Jávea y Villajoyosa, como la zona sur, entre Villajoyosa y San Pedro del Pinatar, mostraban una clara insuficiencia en el número de instalaciones portuarias deportivas, destacando los importantes déficits de amarres que presentaban los municipios de Benidorm y Alicante capital.

- El golf

El segundo gran tipo de equipamientos de ocio que fueron considerados en su momento grandes elementos estructurantes de la oferta turística son los campos de golf.

En efecto, aproximadamente una década después del comienzo del intensísimo desarrollo de los puertos deportivos en el litoral Mediterráneo, el crecimiento de los segmentos de demanda interesados por el deporte del golf provoca el despegue de esta actividad en las regiones turísticas españolas, fundamentalmente la Comunidad Autónoma Andaluza y Cataluña, y, en menor medida, la Comunidad Valenciana.

El gran despegue del golf a escala mundial se produce en la década de los años ochenta, de tal manera que en el año 1990 existen en el mundo unos cuarenta y ocho millones de golfistas y alrededor de veintiséis mil campos. El interés generado por este producto viene dado por el importante poder adquisitivo que poseen sus segmentos de demanda y los efectos multiplicadores intrínsecos. Se ha evaluado que, aproximadamente sólo el $15 \%$ del gasto generado por un turista de golf es un desembolso relacionado directamente con el propio deporte, mientras que alrededor del $40 \%$ son gastos de viaje y alojamiento y el $45 \%$ restante, gastos varios, que incluirían desde la restauración y las compras hasta las excursiones y espectáculos varios (ORTEGA MARTÍNEZ, 1986).

En la provincia de Alicante la implantación de campos de golf se produce a partir de mediados de la década de los años setenta, y se apoya, fundamentalmente, en la ventaja comparativa que ofrece la benignidad climática de las tierras alicantinas para un deporte exige amplios lapsos de permanencia al aire libre.

Existen categorizadas diferentes tipologías de campos de golf atendiendo al tipo de demanda y su relación con el alojamiento turístico ${ }^{10}$ :

— golf de socios, nutrido de población autóctona, originaria de áreas urbanas. Se trata de un fenómeno de ocio de proximidad.

9 SANZ PAREJA, E. (1987): «El turismo náutico en el Mediterráneo», en Estudios Turísticos, nº 93. Madrid, pp. 27-48.

10 Clasificación realizada en estudios sobre el producto golf encargados por el Instituto español de Turismo. Recogido en VERA REBOLLO, J.F. (1991). 
- golf público, debido a iniciativas de este tipo.

- golf urbanización. El negocio es de carácter inmobiliario.

- golf resort, campo asociado a un gran complejo que incluye el alojamiento en el hotel, así como otras ofertas de ocio.

Tal y como señala Vera (1991), es el tercer grupo, golf urbanización, el que interesa particularmente a la Costa Blanca y, al mismo tiempo, se señala el carácter de revulsivo que estos importantes equipamientos han tenido de cara al negocio inmobiliario, «ya no se trata de vender simples conjuntos residenciales, puesto que ahora se vende el campo de golf, una actividad en la que coinciden los intereses de promotores y constructores y de los ayuntamientos que ven disminuir sus ingresos por turismo, que son casi sinónimo de licencias de obras y plusvalías».

Existen en la provincia de Alicante once campos de golf y dos de prácticas, además de varios proyectos de futuras operaciones, entre los que los más destacables tienen como objetivo, en su ubicación, la ociurbe de Benidorm.

CAMPOS DE GOLF EN LA PROVINCIA DE ALICANTE

\begin{tabular}{|c|c|c|c|c|}
\hline Nombre & Ubicación & Número hoyos/par & Recorrido mts. & Año \\
\hline Club de Golf Alenda & $\begin{array}{l}\text { N-330 (Km. 15) } \\
\text { Monforte del Cid }\end{array}$ & $18 / 72$ & 6.150 & 1997 \\
\hline Club de Golf Bonalba & $\begin{array}{l}\text { Ctra. Busot-Mutxamel s/n. } \\
\text { Mutxamel }\end{array}$ & $18 / 72$ & 6.367 & 1993 \\
\hline Club de Golf Don Cayo & $\begin{array}{l}\text { Urbanización El Aramo, s/n. } \\
\text { Altea }\end{array}$ & $9 / 72$ & 6.156 & 1976 \\
\hline Club de Golf El Plantío & $\begin{array}{l}\text { Ctra. Alicante-Elche, Km. } 3 \\
\text { Alicante }\end{array}$ & $\begin{array}{c}9 / 36 \\
18 / 72\end{array}$ & 6.148 & 1993 \\
\hline Club de Golf Ifach & $\begin{array}{l}\text { Urbanización San Jaime } \\
\text { Benissa }\end{array}$ & $9 / 60$ & 1.703 & 1974 \\
\hline Club de Golf Jávea & $\begin{array}{l}\text { Ctra. Jávea-Benitatxell, Km. 4,5 } \\
\text { Jávea }\end{array}$ & $9 / 72$ & 6.070 & 1981 \\
\hline Club de Golf La Marquesa & $\begin{array}{l}\text { Avda. Justo Quesada, s/n } \\
\text { Rojales }\end{array}$ & $18 / 72$ & 5.840 & 1989 \\
\hline Club de Golf La Sella & $\begin{array}{l}\text { Ctra. La Jara-Jesús Pobre } \\
\text { Denia }\end{array}$ & $18 / 72$ & 6.028 & 1991 \\
\hline Club de Golf Las Ramblas de Orihuela & $\begin{array}{l}\text { Ctra. Alicante-Cartagena, Km. } 48 \\
\text { Orihuela }\end{array}$ & $18 / 72$ & 5.770 & 1991 \\
\hline Club de Golf Villamartín & $\begin{array}{l}\text { Ctra. Alicante-Cartagena, Km. } 50 \\
\text { Orihuela }\end{array}$ & $18 / 72$ & 6.132 & 1972 \\
\hline Real Club de Golf Campoamor & $\begin{array}{l}\text { Ctra. Cartagena Alicante, Km. } 48 \\
\text { Orihuela }\end{array}$ & $18 / 72$ & 6.146 & 1989 \\
\hline Campo de práctica de golf Camping Benisol & $\begin{array}{l}\text { Avda. Comunidad Valenciana } \\
\text { Benidorm }\end{array}$ & \multicolumn{3}{|c|}{15 driving ranges } \\
\hline Campo de práctica de golf L'Alfas del Pi & $\begin{array}{l}\text { Playa del Albir } \\
\text { L'Alfas del Pi }\end{array}$ & \multicolumn{3}{|c|}{11 driving ranges } \\
\hline
\end{tabular}

Fuente: Guía de Campos de Golf de la Provincia de Alicante, Costa Blanca, Patronato Provincial de Turismo, Diputación de Alicante, Manual Profesional del turismo de la Costa Blanca, 1997; Cámara Oficial de Comercio, Industria y Navegación de Alicante y Fomento de Turismo de la Costa Blanca; Plan MUNRES. 
En el cuadro anterior se puede observar como en el desarrollo e implantación de campos de golf en la provincia se distinguen dos momentos. Un primer instante, primera mitad de los años setenta, en que se construyen tres campos, y una segunda secuencia, que coincide con el final de la década de los años ochenta y principio de los años noventa.

En el primer caso, dos de los tres campos (Don Cayo e Ifach) son de dimensiones reducidas (nueve hoyos), mientras que Villamartín (el más antiguo de la provincia) es un campo de tamaño habitual. Los tres equipamientos deportivos van asociados a importantes actuaciones de carácter inmobiliario, Urbanización San Jaume en el caso del Club de Golf Ifach, El Aramo para Don cayo y la urbanización del mismo nombre por lo que se refiere al Club de Golf Villamartín.

En la segunda fase, finales de los años ochenta y principio de los noventa, se construyen los campos que configurarán un privilegiado espacio para la práctica de este deporte en el municipio de Orihuela (Real Club de Golf Campoamor y Club de Golf Las Ramblas), La Marquesa, en Rojales, La Sella en Denia, y, poco después, las operaciones que cristalizarán en los campos próximos a la ciudad de Alicante.

De forma global, la tónica será la misma señalada anteriormente, el campo de golf sirve como pretexto para continuar con el negocio inmobiliario, en un momento en que comienza a advertirse el decaimiento de la actividad y, por ende, de la construcción. Las operaciones de carácter inmobiliario subyacen bajo los campos de golf construidos en esos momentos en la comarca del Bajo Segura (el de la Marquesa, por ejemplo, asociado a la urbanización Ciudad Quesada); urbanizaciones con el ilustrativo nombre de Sierra Altea Golf, ejemplifican el sentido de original de estos equipamientos deportivos.

Más recientemente, en los proyectos de Alicante y Mutxamel, la finalidad inmobiliaria de las actuaciones en materia de golf ha seguido presente, no en vano el desarrollo de determinados Programas de Actuación Urbanística (PAU) se condicionó, en su momento, al desarrollo de campos de golf ${ }^{11}$. Una simple ojeada a la publicidad inserta en la prensa local pone de manifiesto esta idea; anuncios como «Bonalba. Casas y golf», «Residencial, Lucentum Golf» ${ }^{12} O$ «Residencial Mediterráneo. Entre el golf y el mar...» son habituales en las últimas fechas.

Sin embargo, es necesario señalar que el producto golf en la provincia de Alicante ha conseguido un cierto éxito, independiente del hecho inmobiliario. Los campos del sur de la provincia, fundamentalmente los oriolanos, han conseguido una considerable clientela, atraída por los innegables atractivos ambientales de la zona, así como por la favorable renta de situación (autopista/autovía A-7, Aeropuerto Internacional de Alicante). Al igual que determinadas actuaciones inmobiliarias aprovechan la existencia de los campos de golf, establecimientos hoteleros de la provincia han creado ofertas, paquetes de golf, que incluyen alojamiento y manutención así como los derechos de juego, configurando de esta manera un verdadero producto turístico.

Así pues, las características que han definido el proceso de instalación de los equipamientos turístico/deportivos que por antonomasia se han considerado como los principales elementos de oferta complementaria, puertos deportivos y campos de golf, han sido:

11 Así ocurre en el caso del PAU 4, en la ciudad de Alicante, o ocurrió en las actuaciones llevadas a cabo en el municipio de Orihuela.

12 El croquis que indica la ubicación del complejo residencial señala al mismo tiempo el emplazamiento del «futuro campo de golf», que no es otro que el Golf Alicante, previsto en el desarrollo del PAU 4. 
- instrumentación inmobiliaria. En la mayoría de los casos estos equipamientos que han sido utilizados como excusa para la venta de chalets, bungalows y apartamentos, a partir de una supuesta cualificación del aparato residencial y su entorno.

- se trata de piezas que en su implantación han tenido un carácter marcadamente local. Cada ayuntamiento ha aspirado a instalar en su término municipal un campo de golf y/o un puerto deportivo, que prestigiase la imagen local. Así pues, estos equipos de ocio se han desarrollado al margen de cualquier criterio o lógica territorial, dispersándose a lo largo de toda la franja litoral.

- los puertos deportivos se han configurado en auténticos enclaves, elementos excluidos física y socialmente de la trama urbana y turística preexistente.

- las instalaciones náutico-deportivas y, en menor medida, los campos de golf no han llegado a configurar, realmente, elementos de oferta complementaria de productos generalistas, ambición que nunca ha tenido sentido, dado el público objetivo a quien se ha dirigido. Por otra parte, el considerable número de puertos deportivos y puntos de amarre no han sido argumento suficiente para constituir productos turísticos náutico-deportivos individualizados.

- el producto del golf en Alicante, definido por el ensamblaje entre la oferta deportiva en sí misma (los campos) y otros elementos de oferta como el alojamiento y de ingredientes de ocio, ha conseguido introducirse en los mercados europeos, además de captar en algunos casos una demanda de ocio de proximidad.

\subsection{Comportamientos de la demanda y tendencias sobre la oferta}

Se ha señalado en párrafos anteriores que desde comienzos de la actual década, y cada vez con una mayor intensidad, se detecta una inclinación de los turistas hacia la práctica de un ocio diferente del conocido. De manera global cabe destacar dos fenómenos que han incidido directamente en la modificación de los comportamientos de la demanda; de un lado lo que definió Urry como, universalización de la mirada turística (URRY:1990), de manera que cualquier espacio es susceptible de un desarrollo turístico (frente a la concentración producida hasta el momento en la denominada periferia del placer), y, en segundo lugar, la difuminación de las barreras existentes entre el turismo y otras actividades como la cultura, el negocio o el comercio, esta última claramente manifestada en el fenómeno de los malls.

De esta manera, mientras la cuota de mercado de los productos de sol y playa masivo se reduce, aumenta la de el turismo de ciudades, turismo de montaña, de campo, o aquellas fórmulas cuyo eje motivacional entronca con cuestiones de salud o razones de prácticas deportivas (AGUILÓ PÉREZ, 1996).

Como resultado de estas modificaciones, se constata la definición de nuevos rasgos en la oferta turística

a) tematización. Los elementos a los que se asimila la idea de tematización son, indiscutiblemente, los grandes parques de ocio. No obstante, los parques temáticos no son las únicas ofertas de ocio que introducen la idea de la tematización. Establecimientos de restauración, comercios, lugares de ocio nocturno e incluso destinos turísticos, como en el caso de la población Empuries, donde utilizando actores y diversos medios técnicos se escenifica la vida cotidiana de la antigua Emporion, han incorporado la tematización como argumento de redefinición de la oferta turística.

Respecto al fenómeno de los parques temáticos, Antón ha destacado la capacidad que poseen estas grandes piezas de ocio para generar dinámicas que pueden llegar a modificar por completo un espacio turístico. Así, la construcción de importantes infraestructuras, la 
modernización de la oferta instalada e incluso de las fórmulas de distribución y comercialización de esta oferta, han sido elementos que han conocido importantes modificaciones en el sector de la Costa Daurada tras la instalación de Port Aventura.

b) adecuación a las potencialidades de los espacios turísticos. La nueva cultura del ocio rechazará aquellas ofertas estereotipadas que, basadas en la reproducción de las mismas fórmulas una y otra vez, puedan ser consumidas en cualquier destino vacacional de la misma manera o, incluso, que no se distingan de aquellas existentes en los lugares de origen.

c) integración de cultura y turismo. En la línea señalada en párrafos anteriores, cultura y turismo aparecen paulatinamente más unidos. A este respecto, Huéscar señala el turismo cultural como una de las características fundamentales que definen las nuevas pautas de comportamiento de las corrientes emisoras turísticas y, más concretamente, el deseo de contacto con las sociedades locales y con las manifestaciones de su cultura.

Esta unión entre turismo y valores culturales se realiza a través de varios vehículos como son la propia teatralización de los recursos o el desarrollo de megaeventos. Otro elemento a considerar como vehículo difusor de la cultura son los museos y, en este sentido, Urry señala que se están produciendo sobre los mismos importantes modificaciones que afectan a los contenidos, preferencias por los temas alternativos (etnografía, rechazo a las historias nacionales), introducción de museos vivos, con incorporación de nuevas tecnologías (3D, realidad virtual, imagen y sonido) y, por último, la musealización de los establecimientos (bares, restaurantes, tiendas), creando escenarios temáticos.

Un importante factor que se introduce en la asimilación entre turismo y cultura es el de la educación que, sumado a la importancia que puede alcanzar por sí misma una oferta educativa que considere como público objetivo matrimonios jóvenes con hijos y centros de enseñanza, representa una oportunidad de creación de nuevos productos desestacionalizadores. Mediante una adecuada distribución y comercialización (Centrales de reserva, agencias especializadas), los mismos elementos señalados como componentes de una nueva oferta complementaria (museos, tematización) pueden configurarse en integrantes básicos de productos educativos orientados a escolares, superando el ámbito local, lo que permitiría la generación de flujos turísticos durante la temporada baja.

\section{Hacia un reequilibrio territorial: la complementariedad de ofertas}

Las nuevas tendencias y comportamientos observados en la demanda turística internacional, permiten considerar la introducción dentro del mercado turístico de espacios que hasta el momento han mantenido una posición marginal en el mismo. La mayor valoración del patrimonio cultural y ambiental, el deseo de practicar un ocio activo o el rechazo a las ofertas estereotipadas, producidas a partir de un modelo estándar, otorgan a muchos espacios de interior el carácter de áreas con un extraordinario potencial turístico.

Sin embargo, parece lógico indicar que no todos los espacios interiores poseerán el suficiente atractivo como para generar flujos turísticos de la magnitud adecuada para hacer del turismo una actividad de fuerte implantación en las economías locales. Las prácticas más exitosas de turismo rural o ecoturismo se desarrollan a partir de la presencia de recursos de gran potencial, con una indudable capacidad de atracción sobre las demandas.

En otra escala de análisis, la subregional, las áreas del traspaís de los espacios litorales que conocen una fuerte implantación del turismo, pueden jugar un importante papel en los procesos de recualificación de los productos turísticos convencionales. En efecto, en casos como el de la provincia de Alicante, con destinos turísticos litorales en fase de madurez y áreas de interior cuyos recursos no poseen un atractivo de gran rango para promover 
desarrollos turísticos endógenos, la complementariedad entre ambos espacios, entre la oferta instalada en el litoral y los recursos del interior, permite el desarrollo de estrategias de cualificación de los espacios turísticos, al incorporar esos espacios del traspaís, que poseen recursos adecuados a las nuevas tendencias de los mercados turísticos, a los productos ya conocidos. Así, con el desarrollo de esta dialéctica litoral-interior se avanza hacia un doble objetivo:

- desarrollo turístico de los espacios interiores, mediante la puesta en valor de los recursos existentes. Obviamente no se trata de reproducir los mismos mecanismos de creación de espacio turístico utilizados en las áreas litorales, si no de enfatizar las grandes posibilidades de ocio que poseen estos lugares.

- diversificación de los productos litorales, mediante la inserción de elementos de oferta ajenos y que entroncan directamente con los nuevos gustos de la demanda.

Un esbozo de las posibilidades que poseen estas fórmulas de complementariedad de espacios y ofertas es el área de influencia turística generada en torno a la ciudad de Benidorm. La ociurbe benidormí es, con más de nueve millones de pernoctaciones anuales, el principal destino de sol y playa del Mediterráneo español. Tras una fase donde se manifestó un claro agotamiento de las fórmulas turísticas que lo sustentaban, Benidorm ha sabido relanzarse como destino turístico mediante el diseño de productos desestacionalizadores, fidelizando a su clientela e incorporando constantemente nuevos argumentos en sus ofertas de ocio. Entre estas nuevas ofertas, en ocasiones no tan nuevas si no que han conocido de un mejor diseño en la actualidad, cabe incluir la incorporación de nuevos recursos y espacios como un complemento del «producto Benidorm». Esta vía de diversificación a través de las complementariedades se desarrolla fundamentalmente, hasta el momento, mediante dos elementos que pueden servir de introducción en la comprensión de los escasamente estudiados procesos de difusión de los efectos del turismo entre los destinos turísticos y su hinterland ${ }^{13}$ o área de influencia (MAPA 4):

- excursiones, generalmente realizadas en autobús, que tienen como origen la población turística, y que sirven como fórmula de integración de otros espacios dentro del producto de ese destino turístico. Se desarrollan durante todo el año y los destinos más habituales son, el pueblo de Castell de Guadalest, las Fuentes del Algar (Callosa d'En Sarrià), Cuevas de Canelobre (Busot), Isla de Tabarca y toda una variedad de lugares que son objeto de una corta visita (entre los que se incluye la propia ciudad de Alicante).

- acciones de la administración, fundamentalmente la local, encaminadas al ensamblaje de productos turísticos que incorporan elementos de oferta de carácter supramunicipal. Entre éstas cabría destacar los convenios de colaboración firmados entre el ayuntamiento de Benidorm y los de Castell de Guadalest, Benissa y Callosa d'En Sarrià, por los cuales Benidorm incluye en su propia promoción las ofertas de estas poblaciones. Asimismo, existe algún folleto promocional elaborado por el Servei Municipal de Turisme de Benidorm (Benidorm y sus alrededores) que incluye la referencia de varias poblaciones alicantinas.

13 Aspectos tales como el desarrollo inmobiliario-turístico en municipios de lo que se ha dado en denominar, segunda línea, (donde frente a la presencia del mar, factor motivacional básico de los desarrollos en municipios de primera línea, son los valores paisajísticos los más valorados) o la configuración de un importante mercado de mano de obra en municipios del traspaís que atenderán las necesidades de los municipios litorales, en un primer momento en la fase de construcción y, posteriormente, como mano de obra escasamente cualificada dedicada a los servicios comerciales, pueden documentarse de manera exhaustiva, entre otras obras, en:

— VERA REBOLLO, J.F.; PONCE HERRERO, G.; DÁVILA LINARES, J.M.; RAMÓN MORTE, A.: (1990). 


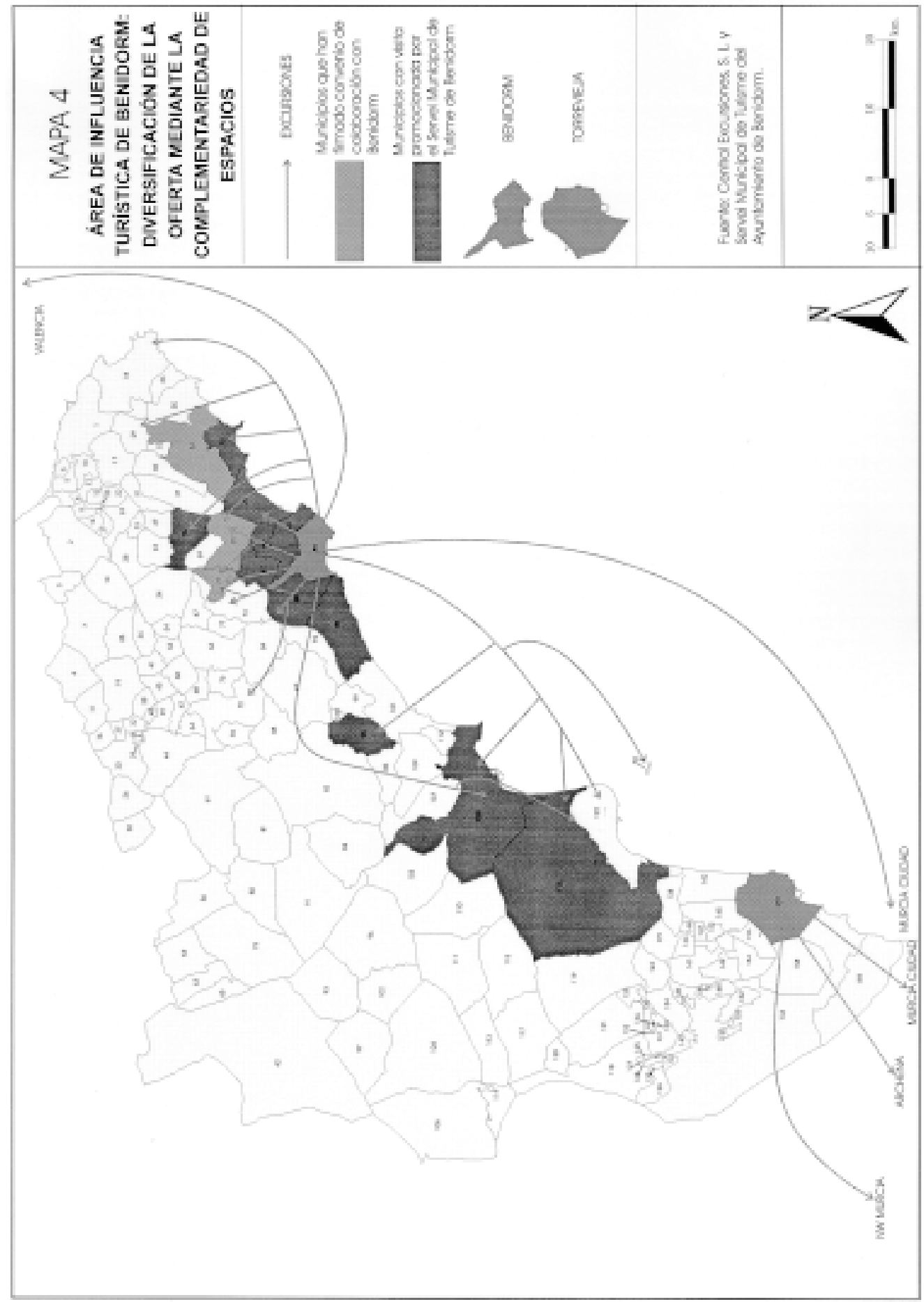


Si bien es cierto que el desarrollo de estas acciones es susceptible de mejoras (arbitraje de fórmulas para que la excursiones reviertan de manera más importante sobre las poblaciones, excesivo control de los operadores, instalación de agencias receptivas por parte de la administración en los destinos, los esfuerzos se orientan de manera casi exclusiva hacia la promoción, folletos poco atractivos), no menos cierto es que gracias a estos elementos poblaciones de muy pequeño rango consiguen un desarrollo turístico, con lo efectos benéficos que ello conlleva y eluden muchos de los impactos que ha generado la implantación de la actividad.

Finalmente, la progresiva incorporación de nuevos municipios a este tipo de desarrollo turístico que aprovecha la oferta instalada en los espacios litorales, ha de tener como principio la elaboración de inventarios y la evaluación de potencialidades de los recursos turísticos, incorporando criterios de sostenibilidad futura de la actividad (ordenación adecuada, capacidad de carga) desde la perspectiva del desarrollo de las sociedades locales, para lo cual es necesario el desarrollo de nuevas fórmulas de comercialización y distribución. De esta manera, el turismo demuestra su marcado carácter de actividad estratégica, pudiendo ser objeto de políticas orientadas hacia objetivos de reequilibrio territorial.

\section{Bibliografía}

AGUILÓ PÉREZ, E. (1996): «Factores de cambio en el turismo: políticas a desarrollar», en Turismo y promoción de destinos turísticos: implicaciones empresariales. Luis Valdés y Agustín Ruiz (Coord.) Universidad de Oviedo, pp. 21-40.

AJUNTAMENT DE CALVIÀ (1988): Calvià a bon Port. Avance del Plan General de Ordenación del Municipio de Calvià. Calvià. 176 pp.

ANTÓN ClAVÉ, S. (1996): «El Parque Temático Port Aventura. Estrategia de producto para la reestructuración de núcleos turísticos consolidados en Cataluña (El papel de la administración como motor del cambio en Salou y Vila-Seca)», Estudios Turísticos no 30, pp. 7-36.

DONAIRE BENITO, J.A. (1996): El turismo a los ojos del postmodernismo. Costa Brava, Tunicia y los malls. Tesis doctoral. Universidad de Girona. 2 vol. 626 pp.+ apéndice. Inédita

DONAIRE BENITO, J.A.; FRAGUELL SANSBELLÓ, R.M.; MUNDET CERDAN, L. (1995): «La nueva configuración espacial del turismo en la Costa Brava» en ¿España un país turísticamente avanzado? I ${ }^{\text {er }}$ Congreso de la AECIT pp. 243-254. AECIT e Instituto de Estudios Turísticos. Marbella.

FUNDACIÓN CAVANILLES DE ALTOS ESTUDIOS TURÍSTICOS (1997): SMART PROGRAM. Case study report: La Marina Baixa. Inédito.

IRIBAS SÁNCHEZ, J.M. (1995): «Consideraciones sobre la situación urbana y turística del litoral alicantino» en Agua y espacios de ocio. Fundación Cultural CAM y Universidad de Alicante. Alicante, pp. 61-90.

JUNTA DE ANDALUCÍA (1993): Plan DIA. Plan de Desarrollo Integral del turismo en Andalucía. Sevilla. $315 \mathrm{pp}$.

ORTEGA MARTÍNEZ, E. (1986): «Presente y futuro del turismo de golf en España», en Estudios Turísticos $\mathrm{n}^{\circ} 90$, pp. 23-46.

SANZ PAREJA, E. (1987): «El turismo náutico en el Mediterráneo», en Estudios Turísticos, nº 93. Madrid, pp. 27-48.

TORRES ALFOSEA, F.J. Ordenación del litoral en la Costa Blanca. Ed. Universidad de Alicante. (En prensa).

TORRES BERNIER, E. (1996): «Las megatendencias en el sector turístico», en Turismo y promoción de destinos turísticos: implicaciones empresariales. Luis Valdés y Agustín Ruiz (Coord.), pp. 11-20. Universidad de Oviedo.

URRY, J. (1990): The tourist gaze. Leisure and travel in contemporary societies. Sage Publications. Londres.

VERA REBOLLO, J.F. (1991): «La oferta complementaria en el turismo de sol y playa: una 
respuesta al agotamiento al modelo masivo en la Costa Blanca», en Ordenación y Desarrollo del turismo en España y Francia, Casa de Velázquez, MOPU y otros, Madrid, pp. 91-99.

VERA REBOLLO, J.F.; CRUZ OROZCO, J.; BAÑOS CASTIÑEIRA, C.J., (1995): «Turismo y organización del territorio: desajustes de un modelo de implantación y nuevas estrategias» en Cuadernos de Geografía n 58 Políticas Territoriales Valencianas Departamento de Geografía, Universidad de Valencia, pp. 439-474.

VERA REBOLLO, J.F.; PONCE HERRERO, G.; DÁVILA LINARES, J.M.; RAMÓN MORTE, A. (1990): «Evaluación del grado de especialización turística de los municipios litorales valencianos» en Investigaciones Geográficas $\mathrm{n}^{\circ}$ 8, Instituto Universitario de Geografía, Universidad de Alicante, pp. 83-112. 
